\title{
The hypoxia signaling pathway and hypoxic adaptation in fishes
}

\author{
XIAO Wuhan \\ Key Laboratory of Aquatic Biodiversity and Conservation, Institute of Hydrobiology, Chinese Academy of Sciences, Wuhan 430072, China
}

Received September 18, 2014; accepted November 6, 2014; published online January 15, 2015

\begin{abstract}
The hypoxia signaling pathway is an evolutionarily conserved cellular signaling pathway present in animals ranging from Caenorhabditis elegans to mammals. The pathway is crucial for oxygen homeostasis maintenance. Hypoxia-inducible factors (HIF-1 $\alpha$ and HIF-2 $\alpha$ ) are master regulators in the hypoxia signaling pathway. Oxygen concentrations vary a lot in the aquatic environment. To deal with this, fishes have adapted and developed varying strategies for living in hypoxic conditions. Investigations into the strategies and mechanisms of hypoxia adaptation in fishes will allow us to understand fish speciation and breed hypoxia-tolerant fish species/strains. This review summarizes the process of the hypoxia signaling pathway and its regulation, as well as the mechanism of hypoxia adaptation in fishes.
\end{abstract}

hypoxia, hypoxia-inducible factors, PHDs, pVHL, FIH, fish

Citation: Xiao WH. The hypoxia signaling pathway and hypoxic adaptation in fishes. Sci China Life Sci, 2015, 58: 148-155, doi: 10.1007/s11427-015-4801-z

Approximately 2.5 billion years ago, photosynthesis led to the accumulation of oxygen to levels that were likely toxic to many obligate anaerobes. However, increased availability of atmospheric $\mathrm{O}_{2}$ led to the evolution of an extraordinarily efficient system of oxidative phosphorylation. In this system, chemical energy stored in the carbon bonds of organic molecules is transferred to the high-energy phosphate bond in ATP, which is then used to power physicochemical reactions in living cells [1]. Additionally, $\mathrm{O}_{2}$ serves as the final electron acceptor in oxidative phosphorylation, which is not only required for energy production, but is also the direct substrate of many enzymes. Thus, it is critical for the growth, development, and reproduction of organisms. Consequently, metazoans have evolved complicated systems of cellular metabolism and physiology to maintain oxygen homeostasis and have developed a biochemical response to low oxygen levels [2]. There are a number of oxygen-sensing pathways that promote hypoxia tolerance by activating transcription and inhibiting translation: the energy and nutrient sensor mTOR, the unfolded protein re-

email:w-xiao@ihb.ac.cn sponse that activates the endoplasmic stress response, and the nuclear factor (NF)- $\kappa \mathrm{B}$ transcriptional response [3]. However, hypoxia-inducible factors (HIFs) are recognized as master regulators of the cellular response to hypoxic stress $[4,5]$.

The hypoxia signaling pathway is evolutionarily conserved from Caenorhabditis elegans to human beings and it activates similar or homogenous gene expression, resulting in similar physical and biochemical responses. Compared with the terrestrial environment, oxygen concentrations vary greatly in the aquatic environment [6]. Thus, compared with most birds and mammals, fishes are tolerant of this varying oxygen availability. Natural selection by oxygen concentration has facilitated the evolution of fishes with a range of adaptations to variable oxygen concentration. Even in waters at the same latitude, closely related species or different strains within a species exhibit varied adaptations to oxygen concentration. Additionally, closely related fishes distributed in waters at different latitudes exhibit extensive variation in their tolerance of hypoxia. Determining the mechanisms of hypoxia adaptation in fishes will not only help us to un- 
derstand fish speciation and the evolution of the hypoxia signaling pathway, but will also guide us in the breeding of hypoxia-tolerant fish species/strains.

\section{HIF and the regulation of the hypoxia sig- naling pathway}

HIF is a master regulator in the hypoxia signaling pathway and is expressed by all extant metazoan species analyzed to date. HIF is a heterodimer comprising an oxygen-labile $\alpha$-subunit (HIF- $\alpha$ ) and a constitutively expressed $\beta$-subunit (HIF- $\beta$ or ARNT). Each unit contains the basic helix-loop-helix-PAS (bHLH-PAS) domains, which mediate the formation of heterodimers and DNA binding. HIF- $\beta$ dimerizes with other bHLH-PAS proteins and is stably expressed, but HIF- $\alpha$ determines HIF-1 transcriptional activity $[1,4,7]$.

Under normoxia (normal oxygen tension), either HIF-1 $\alpha$ or HIF- $2 \alpha$ is hydroxylated on specific conserved proline residues by prolyl-hydroxylase domains (PHDs), which contain enzymes (including PHD1, PHD2, and PHD3; PHD2 is thought to be essential), using molecular oxygen as a substrate [8]. In the reaction, one oxygen atom is inserted into the prolyl residue; a second atom is inserted into the co-substrate $\alpha$-ketoglutarate, splitting it into $\mathrm{CO}_{2}$ and succinate. Hydroxy-HIF- $\alpha$ is recognized by von Hippel-Lindau tumor suppressor protein (pVHL) and is subsequently ubiquitylated by the VBC ubiquitin-ligase complex, marking HIF- $\alpha$ for degradation by the $26 \mathrm{~S}$ proteasome [9]. However, under hypoxic conditions, PHD catalytic activity is inhibited by the lack of oxygen and HIF- $\alpha$ is not hydroxylated, thus, HIF- $\alpha$ is not recognized by the VBC complex, allowing HIF- $\alpha$ to stabilize. Stable HIF- $\alpha$ is transferred into the nucleus and heterodimerizes with stable HIF-1 $\beta$. HIF heterodimers recognize and bind to hypoxia response elements (HREs) in the genome with the consensus sequence G/ACGTG to regulate the transcription of genes together with co-activators such as $\mathrm{CBP} / \mathrm{p} 300$, resulting in a series of physical and biochemical responses (Figure 1) [1,4].

Because HIF- $\alpha$ plays such an important role in the hypoxia signaling pathway, HIF- $\alpha$ modulation is assumed to be a major mechanism for the regulation of the hypoxia signaling pathway. HIF- $\alpha$ modulation includes transcription regulation and post translation modulation (PTM). At present, there are few reports on HIF- $\alpha$ transcription regulation. Those available mainly focus on post translation HIF- $\alpha$ modulation. NF- $\kappa \mathrm{B}$ activates HIF- $1 \alpha$ expression, linking innate immunity to the hypoxic response [10]. HIF- $\alpha$ PTM is exhibited in many pathways. Apart from VHL-mediated HIF- $\alpha$ proteasomal degradation, HIF- $\alpha$ is modulated by acetylation/deacetylation, phosphorylation/de-phosphorylation [11], sumoylation, and neddylation [12]. Histone acetyltransferase p300/CBP enhances HIF-1 $\alpha$ transcriptional activity by interacting with the HIF-1 $\alpha$ C-terminus [13].

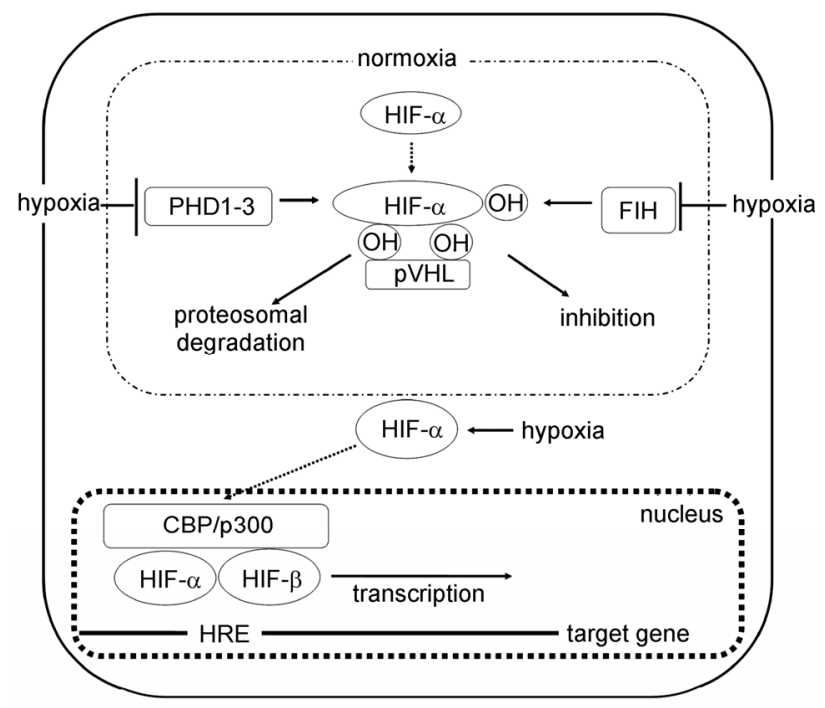

Figure 1 Hypoxia signaling pathway.

NAD+ dependent-deacetylase, Sirt1, Sirt3, Sirt6, and Sirt7 regulate HIF- $\alpha$ activity either positively or negatively, playing important roles in cell metabolism, life span, tumorigenesis, and cardiovascular disease [14-21]. As reported by Shao et al. [22] hypoxia stimulates an increase in mRNA and SUMO-1 protein levels. SUMO-1 co-localize with HIF- $1 \alpha$ in the nucleus to induce HIF- $1 \alpha$ sumoylation, resulting in the stabilization and enhancement of HIF-1 $\alpha$ transcriptional activity [22-24].

Furthermore, even though some HIF- $1 \alpha$ and HIF- $2 \alpha$ interacting proteins cannot modify HIF- $1 \alpha$ and HIF-2 $\alpha$, they can regulate their stability and transcriptional activity either positively or negatively via specific mechanisms. PKM2 enhances HIF-1 $\alpha$ transcriptional activity through recruiting p300; PHD3 enhances PKM2 activity as a co-activator by hydroxylating PKM2 [25]. SHARP1 promotes HIF- $\alpha$ degradation by serving as the HIF-presenting factor to the proteasome [26]. EAF2 is a specific HIF-1 $\alpha$ downstream target, which interacts with HIF- $1 \alpha$ but not HIF- $2 \alpha$, resulting in the inhibition of HIF- $1 \alpha$ transcriptional activity via preventing p300 from binding to HIF-1 $\alpha$ [27]. Other proteins do not interact with HIF- $\alpha$ directly, but interact with other factors that regulate HIF- $\alpha$, e.g., pVHL and PHDs among others. These proteins indirectly regulate HIF- $\alpha$ activity. E3 ligase Siah2 affects cellular HIF-1 $\alpha$ protein levels and mediates the hypoxic response through regulating PHD protein stability [28]. E2-EPF UCP targets pVHL for degradation to control the HIF-1 $\alpha$ stability [29]. PML inhibits HIF-1 $\alpha$ translation through mTOR repression [30]. SENP3 is responsible for the enhancement of HIF-1 transactivation under mild oxidative stress via de-sumoylation [31]. The LIMD1 protein bridges an association between the PHDs and VHL to inhibit HIF-1 activity [32].

In summary, as a master regulator of the hypoxia signaling pathway, the direct or indirect regulation of HIF- $\alpha$ plays 
key roles in the pathway. Moreover, $\mathrm{HIF}-\alpha$ regulation is currently an area of intense study [7].

\section{Hypoxic adaptation strategies in fish}

Oxygen concentration varies greatly in aquatic environments depending on the geographic location, season, composition, and water flow. Fishes have evolved different adaptive strategies with the 20,000 extant species varying greatly in hypoxia tolerance. Fishes that depend on aerobic metabolism for rapid swimming, such as salmon and tuna, are moderately to extremely sensitive to hypoxia, whereas carp, eels, and hagfish can live comfortably in hypoxic conditions [6]. Hypoxic adaptation in fishes can be attributed to long-term adaptation and the acute response.

\subsection{Fish adaptation strategies to long-term hypoxia}

To adapt to varying oxygen levels in the long-term, fishes usually undergo gene mutations that induce changes in physical and biochemical responses, and tissue and organ structure, resulting in three basic capabilities: (a) to decrease metabolic rate under hypoxia, (b) tolerance to increased levels of metabolic by-products, and (c) to avoid and/or repair cellular injury during re-oxygenation [6].

The first long-term hypoxia adaption strategy in fishes is either to modify respiratory organs or develop accessory organs in addition to gills. For example, loaches have developed the ability to breathe through the skin and intestine, and eels through the mouth and epithelia of cavum larynges.

The second strategy is to modify the metabolic pathway. The crucian carp (Carassius carassius) is the greatest extreme hypoxia tolerant species, enduring months of hypoxia at low temperatures [33]. Their cousins, common goldfish, have half-lethal times of $45 \mathrm{~h}$ under anoxia at $5^{\circ} \mathrm{C}$ and $22 \mathrm{~h}$ at $20^{\circ} \mathrm{C}$. Under hypoxia, strong metabolic depression is key to the survival of these Carassius species [34-36]. Under anoxia, the crucian carp can metabolize anaerobically and convert lactate to ethanol and $\mathrm{CO}_{2}$. These end products can be excreted into the water through the gills. Unlike the dormant turtles, the crucian carp remains active during both hypoxia and anoxia [35]. The main reason is that crucian carp can take advantage of large muscle and liver glycogen reserves, reduced metabolism, and avoidance of lactic acidosis by converting lactate to ethanol and $\mathrm{CO}_{2}$ [34,37].

Yet another strategy is to increase the number of red blood cells and promote the oxygen-carrying capabilities of hemoglobin [38]. During their evolution, fishes have been undergone genetic segregation many times, resulting in huge diversity in the structure and function of genes related to hypoxia adaptation. In carp, HIF- $\alpha$ is duplicated. Even though one copy retains the ancient hypoxia response, a second copy increases hypoxia-sensitivity. This phenomenon indicates that HIF- $\alpha$ in carp has differentiated function- ally during speciation [39]. Furthermore, Chi et al. [40] found different evolutionary patterns of HIF- $\alpha$ isoforms in the basal branches of the Actinopterygii and Sarcopterygii.

\subsection{The acute hypoxia stress response in fishes}

Acute hypoxia stress occurs with temperature, seasonal, and compositional changes in water, particularly in high-density aquaculture situations. Fishes respond to acute hypoxia strongly. First, they try to get more oxygen by breathing directly through the mouth, this is usually referred to as floating heads.

Second, they alter the shape and structure of the gill to enhance oxygen exchange [41-46]. Some fishes alter the cardiac K(ATP) channel, metabolic rate, and increase the number of red blood cells $[47,48]$.

Even though fishes can have an acute reaction to acute hypoxia to maintain normal physical activity, a sudden lack of oxygen will result in mortality. In aquaculture this is referred to as turning pond. The brain and cardiac cells of fishes go through apoptosis under hypoxia, this is the main cause of turning pond. Compared with other vertebrates, some of the key factors in the hypoxia signaling pathway control this physical process [49].

Elucidating the reasons and mechanisms of fish mortality under acute hypoxia will help to prevent or diminish yield losses in aquaculture.

\subsection{The regulatory network of fish genes in response to hypoxia}

Because of their specific habits, investigating the hypoxia signaling pathway and the key factors in its regulatory network in different fish species is necessary. To date, some key factors related to fish hypoxia adaptation and the hypoxia signaling pathway have been identified (Table 1).

\subsubsection{Hypoxia-inducible factors}

Fishes possess homologs of HIF- $\alpha$ and HIF- $\beta$, which paly similar roles in mammals. The fish HIF- $1 \alpha$ sequence, which encodes a protein of 766 amino acids and includes basic-helix-loop-helix, PAS, and ODD domains of HIF $\alpha$-subunits, was first reported from rainbow trout [50]. To date, HIF-1 $\alpha$ sequences have been reported in several fish species, e.g., Atlantic croaker (Micropogonias undulatus) [51], zebrafish (Danio rerio) [52], Wuchang bream (Megalobrama amblycephala) [53], scale-less carp (Gymnocypris przewalskii) [54], ruff (Gymnocephalus cernuus), flounder (Platichthys flesus), perch (Perca fluviatilis), stickleback (Gasterosteus aculeatus), Russian sturgeon (Acipenser gueldenstaedtii) [55], sea bass (Dicentrarchus labrax) [56], Indian catfish (Clarias batrachus) [57], and channel catfish (Ictalurus punctatus) [58]. Additionally, HIF-2 $\alpha$ has been identified in zebrafish [52], Atlantic croaker [51], grass carp (Ctenopharyngodon idella) [59], Indian catfish [57], and 
Table 1 Hypoxia signaling proteins in fishes

\begin{tabular}{ll}
\hline Gene name & \multicolumn{1}{c}{ Fishes } \\
\hline & Oncorhynchus mykiss \\
& Micropogonias undulates \\
& Danio rerio \\
& Megalobrama amblycephala \\
& Gymnocypris przewalskii \\
& Gymnocephalus cernuus \\
& Platichthys flesus \\
& Perca fluviatilis \\
& Gasterosterus aculeatus \\
& Acipencer gueldenstaedtii \\
& Dicentrarchus labrax \\
& Clarias batrachus \\
& Ictalurus punctatus \\
& Danio rerio \\
& Micropogonias undulates \\
& Ctenopharyngodon idellus \\
& Clarias batrachus \\
& Ictalurus punctatus \\
& Danio rerio \\
& Ictalurus punctatus \\
& Salmo salar \\
& Oreochromis niloticus \\
\hline & Danio rerio \\
& Ictalurus punctatus \\
\hline & Danio rerio \\
\hline & \\
&
\end{tabular}

channel catfish [58].

Because of HIF- $\alpha$ 's important role in the hypoxia signaling pathway, the relationship between HIF expression and hypoxia has been investigated in several fishes. Eurasian perch (Perca fluviatilis) is a hypoxia-sensitive fresh water fish in which acute hypoxia can induce HIF-1 $\alpha$ expression in the brain and liver, whereas chronic hypoxia leads to a significant change in HIF-1 $\alpha$ expression in muscle [60]. The Indian catfish is a hypoxia-tolerant species, in which short-term exposure to hypoxia induces HIF- $1 \alpha$ and HIF- $2 \alpha$ expression in the brain, liver, and kidney, whereas the long-term exposure induces HIF-1 $\alpha$ expression in the spleen and HIF-2 $\alpha$ expression in muscle [57]. Furthermore, in channel catfish, another hypoxia-tolerant fish, HIF- $\alpha$ mRNA expression decreases under hypoxia for the first 1.5 $\mathrm{h}$ and then increases after $5 \mathrm{~h} \mathrm{[42].}$

The prolyl hydroxylase (PHD) proteins belong to the $\mathrm{Fe}$ (II) and 2-oxoglutarate-dependent oxygenase superfamily, whose activities are closely associated with oxygen levels. Thus, they are considered oxygen sensors [61]. To date, PHD sequences have been reported in some fish species, such as Atlantic salmon, channel catfish, Nile tilapia, and zebrafish [62]. Even though little is known about the function of fish PHDs, they are thought to act similarly to those of other organisms, which play important roles in HIF- $\alpha$ stability.

\subsubsection{Hypoxia-inducible factor asparaginyl hydroxylase (FIH-1)}

FIH-1, similar to PHD family members, is also a hydroxylase. However, FIH-1 cannot cause HIF- $\alpha$ proteasomal degradation after hydroxylating HIF- $\alpha$. FIH-1 can inhibit the recruitment of the transcriptional coactivators p300/CBP. To date, FIH-1 sequences have been identified in zebrafish [63] and channel catfish [58].

\subsubsection{VHL}

VHL belongs to a component of the VBC E3 ligase complex, which acts as an E3 ligase. Under normoxia, pVHL recognizes hydroxylated HIF- $\alpha$ and causes HIF- $\alpha$ proteasomal degradation. Therefore, $\mathrm{pVHL}$ plays an important role in the regulation of the hypoxia signaling pathway. To date, zebrafish VHL is well studied. VHL-mutant zebrafish have been identified through mutant screening. Similar to that of pVHL-null mice, VHL-mutant zebrafish are embryonically lethal and develop erythrocytosis [64].

\section{Hypoxia adaptation mechanisms in fishes}

The key adaptation to long-term hypoxia is a reduction in metabolic rate and demands. However, whether or not anoxic survival is associated with reductions in both ATP production and use remains unclear. Protein synthesis consumes a lot of ATP. For hypoxia-tolerant crucian carp, the rate of protein synthesis decreases rapidly under both hypoxia and anoxia; however, in hypoxia-sensitive fishes, the rate of protein synthesis remains constant. In this process, AMPK might function as a sensor that regulates protein synthesis under hypoxia. When intracellular AMP is increased, AMPK is activated; whereas when intracellular AMP is decreased, AMPK is inhibited. Moreover, AMPK is also regulated by phosphorylation [65].

Adenosine is a low-oxygen signal. In the hypoxia-tolerant fishes, such as the crucian carp, adenosine has a powerful depressant effect on protein synthesis and $\mathrm{Na}^{+}-\mathrm{K}^{+}$ ATPase activity [66]. Adenosine receptor blockade in the crucian carp results in a threefold increase in ethanol release [67]. Additionally, adenosine and adenosine receptor blockers have surprising impacts on cerebral blood flow. In the crucian carp, cerebral blood flow increases 2.2-fold during anoxia, and superfusing the brain with aminophylline abolishes this increase. Thus, adenosine seems to be an important anoxic signal mediating vasodilation and cerebral blood flow [68].

Tolerance of acidic metabolic end products is another mechanism for fish hypoxia tolerance. The crucian carp can use ethanol as an anaerobic end product. Under anoxia, they maintain ion gradients in hepatocytes and convert lactate to ethanol. Ethanol can be eliminated by diffusion across the gills, avoiding lactic acid accumulation [69].

A most significant issue in low oxygen tolerance is the 
avoidance of free-radical-mediated injury during reoxygenation. In some species, such as the crucian carp, the constitutive expression of defense molecules is not remarkable; it is increased only during hypoxia/reoxygenation [70]. Under anoxia, antioxidant enzyme activity increases, whereas most other enzyme activities, e.g., brain Se-GPX, liver catalase, and G6PDH, do not [71]. After several hours of extreme hypoxia, liver, brain, and gill superoxide dismutase (SOD) activity increases in carp, Cyprinus carpio [72].

Identifying the HIF- $\alpha$ down-stream targets and determining their functions will elucidate hypoxia adaptation mechanisms in fishes. Zhong et al. [73] have identified some hypoxia induced genes, e.g., ERO1-L, p53, CPO, HO-1, MKP2, PFK-2, cystatin B, Glut1, BTG1, TGF-beta1 and PGAM1, in crucian carp blastulae embryonic cells by suppression subtractive hybridization. Liao et al. [74] carried out transcriptome analysis for crucian carp and found hypoxia induced genes related to glycolysis/gluconeogenesis. Everett et al. [75] analyzed the effect of short-term hypoxic exposure on metabolic gene expression. Additionally, Chen et al. [76] analyzed hypoxia-induced changes in the zebrafish skeletal muscle proteome.

To date, many hypoxia-induced genes related to fish hypoxia adaptation have been identified and reported. GLUTs (Glucose transporters) are hypoxia-induced, metabolic genes that facilitate cellular glucose uptake. Under hypoxia, GLUTs are induced to enhance glucose transport, resulting in cellular energy demands. The full length cDNA of grass carp GLUT1, which is highly expressed under hypoxia, has been cloned [77]. When Atlantic cod were exposed to a hypoxic challenge, GLUT1 expression in the gill was significantly up-regulated [78]. Terova et al. [79] found GLUT2 mRNA changes in response to hypoxia in sea bass, a hypoxia-sensitive species, supporting the view that GLUT2 is involved in the hypoxia adaptation response.

Erythropoietin (Epo) is a hypoxia-induced gene related to erythropoiesis, which is a glycoprotein hormone that controls red blood cell production. The first Epo gene fish cloned was that of the pufferfish (Fugu; Takifugu rubripes). In Fugu, Epo is induced by hypoxia and is mainly expressed in the heart [80-82]. However, in other teleost fishes, such as rainbow trout, carp, and eel, Epo was expressed in the kidney, the kidney is the major organ for erythropoiesis in fishes [83].

VEGF is a hypoxia-induced gene related to angiogenesis, which stimulates the proliferation of blood vessels to increase oxygen supply. In the orange-spotted grouper (Epinephelus coioides), hypoxia can induce VEGF expression, which in turn increases oxygen delivery. Hypoxia also induces VEGF expression in salmon $[84,85]$.

Both different cell lines and the zebrafish model have been employed to determine the function of hypoxia-induced genes. Wang et al. [86] cloned the hypoxia-induced HO-1 gene in the crucian carp. Using cell lines, they found that HO-1 plays an important role against hy- poxia-induced cell death. Feng et al. [49] found that zebrafish p53 can protect hypoxia-induced cell death by suppressing BNIP3 expression, a hypoxia-induced cell death gene. Additionally, HIF- $1 \alpha$ is crucial for early zebrafish embryogenesis, particularly for neural crest chemotaxis and the central nervous system $[87,88]$.

Compared with the mouse model, gene knock-out assays in zebrafish are difficult to perform due to lack of suitable zebrafish embryonic stem cell lines. Thus, little is known about the in vivo function of hypoxia-adaptation-related genes in fishes. Recently, TALEN and CRISP/Cas9 techniques have been established and rapidly developed, making knocking out gene assays in zebrafish more convenient. Therefore, information on the in vivo function of hypoxiaadaptation-related genes in fishes is bound to be available in the near future [89]. As a result of differing degrees of pollution in aquaculture waters, protecting the aquatic environment, intensive cultivation modes such as intensive pond aquaculture, and industrial aquaculture have become fundamental to aquaculture in China. Avoiding water pollution is the main means of increasing density and yield per unit of water body. Because of the increase in aquaculture density and yield, it is necessary to improve fish species/strains hypoxia tolerance capabilities.

To breed new fish species or strains with higher hypoxia tolerance, we must first determine the mechanisms of hypoxia tolerance and adaptation in fish. Here are some basic strategies: First, comparative omics, such as genomics, transcriptomics, and proteomics to compare different hypoxia-tolerant fish species distributed in the same waters, or closely related species distributed in different waters with varying oxygen concentration. Second, microarray, transcriptome sequencing, and proteomics to analyze the representative hypoxia-sensitive and tolerant species following hypoxia treatment. Subsequently, using bioinformatic methods, the gene regulatory network for fish hypoxia adaptation and tolerance can be constructed and the key genes identified. By taking advantage of gene function analysis approaches, the functions of key genes can be elucidated, the gene's contributions to fish hypoxia tolerance can be estimated, and the molecular markers related to hypoxia adaptation and tolerance can be screened. Based on these data, we can breed new species or strains with higher hypoxia tolerance using either transgenic techniques or classic hybridization.

1 Semenza GL. Hypoxia-inducible factors in physiology and medicine. Cell, 2012, 148: 399-408

2 Semenza GL. Oxygen sensing, hypoxia-inducible factors, and disease pathophysiology. Ann Rev Pathol, 2014, 9: 47-71

3 Majmundar AJ, Wong WJ, Simon MC. Hypoxia-inducible factors and the response to hypoxic stress. Mol Cell, 2010, 40: 294-309

4 Dunwoodie SL. The role of hypoxia in development of the mammalian embryo. Dev Cell, 2009, 17: 755-773

5 Schofield CJ, Ratcliffe PJ. Oxygen sensing by HIF hydroxylases. Nat 
Rev Mol Cell Biol, 2004, 5: 343-354

6 Bickler PE, Buck LT. Hypoxia tolerance in reptiles, amphibians, and fishes: life with variable oxygen availability. Ann Rev Pathol, 2007, 69: $145-170$

7 Greer SN, Metcalf JL, Wang Y, Ohh M. The updated biology of hypoxia-inducible factor. EMBO J, 2012, 31: 2448-2460

8 Aragones J, Fraisl P, Baes M, Carmeliet P. Oxygen sensors at the crossroad of metabolism. Cell Metab, 2009, 9: 11-22

9 Kaelin WG. Von Hippel-Lindau disease. Ann Rev Pathol, 2007, 2: 145-173

10 Rius J, Guma M, Schachtrup C, Akassoglou K, Zinkernagel AS, Nizet V, Johnson RS, Haddad GG, Karin M. NF-kappaB links innate immunity to the hypoxic response through transcriptional regulation of HIF-1alpha. Nature, 2008, 453: 807-811

11 Flugel D, Gorlach A, Michiels C, Kietzmann T. Glycogen synthase kinase 3 phosphorylates hypoxia-inducible factor lalpha and mediates its destabilization in a VHL-independent manner. Mol Cell Biol, 2007, 27: 3253-3265

12 Ryu JH, Li SH, Park HS, Park JW, Lee B, Chun YS. Hypoxia-inducible factor alpha subunit stabilization by NEDD8 conjugation is reactive oxygen species-dependent. J Biol Chem, 2011, 286: 6963-6970

13 Sang N, Fang J, Srinivas V, Leshchinsky I, Caro J. Carboxyl-terminal transactivation activity of hypoxia-inducible factor 1 alpha is governed by a von Hippel-Lindau protein-independent, hydroxylationregulated association with p300/CBP. Mol Cell Biol, 2002, 22: 2984-2992

14 Mehta R, Steinkraus K A, Sutphin GL, Ramos FJ, Shamieh LS, Huh A, Davis C, Chandler-Brown D, Kaeberlein M. Proteasomal regulation of the hypoxic response modulates aging in $C$. elegans. Science. 2009, 324: 1196-1198

15 Chen D, Thomas EL, Kapahi P. HIF-1 modulates dietary restriction-mediated lifespan extension via IRE-1 in Caenorhabditis elegans. PLoS Genet, 2009, 5: e1000486

16 Zhong L, D'Urso A, Toiber D, Sebastian C, Henry RE, Vadysirisack DD, Guimaraes A, Marinelli B, Wikstrom JD, Nir T, Clish CB, Vaitheesvaran B, Iliopoulos O, Kurland I, Dor Y, Weissleder R, Shirihai OS, Ellisen LW, Espinosa JM, Mostoslavsky R. The histone deacetylase Sirt6 regulates glucose homeostasis via Hif1alpha. Cell, 2010, 140: 280-293

17 Lim JH, Lee YM, Chun YS, Chen J, Kim JE, Park JW. Sirtuin 1 modulates cellular responses to hypoxia by deacetylating hypoxia-inducible factor 1alpha. Mol Cell, 2010, 38: 864-878

18 Dioum EM, Chen R, Alexander MS, Zhang Q, Hogg RT, Gerard RD, Garcia JA. Regulation of hypoxia-inducible factor 2alpha signaling by the stress-responsive deacetylase sirtuin 1. Science, 2009, 324: 1289-1293

19 Gomes AP, Price NL, Ling AJ, Moslehi JJ, Montgomery MK, Rajman L, White JP, Teodoro JS, Wrann CD, Hubbard BP, Mercken EM, Palmeira CM, de Cabo R, Rolo AP, Turner N, Bell EL, Sinclair DA. Declining NAD(+) induces a pseudohypoxic state disrupting nuclear-mitochondrial communication during aging. Cell, 2013, 155: $1624-1638$

20 Hubbi ME, Hu H, Kshitiz Gilkes DM, Semenza GL. Sirtuin-7 inhibits the activity of hypoxia-inducible factors. J Biol Chem, 2013, 288: 20768-20775

21 Finley LW, Carracedo A, Lee J, Souza A, Egia A, Zhang J, Teruya-Feldstein J, Moreira PI, Cardoso SM, Clish CB, Pandolfi PP, Haigis MC. SIRT3 opposes reprogramming of cancer cell metabolism through HIF1alpha destabilization. Cancer Cell, 2011, 19: 416-428

22 Shao R, Zhang FP, Tian F, Anders Friberg P, Wang X, Sjoland H, Billig H. Increase of SUMO-1 expression in response to hypoxia: direct interaction with HIF-1alpha in adult mouse brain and heart in vivo. FEBS Lett, 2004, 569: 293-300

23 Carbia-Nagashima A, Gerez J, Perez-Castro C, Paez-Pereda M, Silberstein S, Stalla GK, Holsboer F, Arzt E. RSUME, a small RWD-containing protein, enhances SUMO conjugation and stabilizes HIF-1alpha during hypoxia. Cell, 2007, 131: 309-323
24 Cheng J, Kang X, Zhang S, Yeh ET. SUMO-specific protease 1 is essential for stabilization of HIF1alpha during hypoxia. Cell, 2007, 131: 584-595

25 Luo W, Hu H, Chang R, Zhong J, Knabel M, O'Meally R, Cole RN, Pandey A, Semenza GL. Pyruvate kinase M2 is a PHD3-stimulated coactivator for hypoxia-inducible factor 1 . Cell, 2011, 145: 732-744

26 Montagner M, Enzo E, Forcato M, Zanconato F, Parenti A, Rampazzo E, Basso G, Leo G, Rosato A, Bicciato S, Cordenonsi M, Piccolo S. SHARP1 suppresses breast cancer metastasis by promoting degradation of hypoxia-inducible factors. Nature, 2012, 487: 380-384

27 Chen Z, Liu X, Mei Z, Wang Z, Xiao W. EAF2 suppresses hypoxia-induced factor 1alpha transcriptional activity by disrupting its interaction with coactivator $\mathrm{CBP} / \mathrm{p} 300$. Mol Cell Biol, 2014, 34: 1085-1099

28 Nakayama K, Frew IJ, Hagensen M, Skals M, Habelhah H, Bhoumik A, Kadoya T, Erdjument-Bromage H, Tempst P, Frappell PB, Bowtell DD, Ronai Z. Siah2 regulates stability of prolyl-hydroxylases, controls HIF1alpha abundance, and modulates physiological responses to hypoxia. Cell, 2004, 117: 941-952

29 Jung CR, Hwang KS, Yoo J, Cho WK, Kim JM, Kim WH, Im DS. E2-EPF UCP targets pVHL for degradation and associates with tumor growth and metastasis. Nat Med, 2006, 12: 809-816

30 Bernardi R, Guernah I, Jin D, Grisendi S, Alimonti A, TeruyaFeldstein J, Cordon-Cardo C, Simon MC, Rafii S, Pandolfi PP. PML inhibits HIF-1alpha translation and neoangiogenesis through repression of mTOR. Nature, 2006, 442: 779-785

31 Huang C, Han Y, Wang Y, Sun X, Yan S, Yeh ET, Chen Y, Cang H, Li H, Shi G, Cheng J, Tang X, Yi J. SENP3 is responsible for HIF-1 transactivation under mild oxidative stress via p300 de-SUMOylation. EMBO J, 2009, 28: 2748-2762

32 Foxler DE, Bridge KS, James V, Webb TM, Mee M, Wong SC, Feng Y, Constantin-Teodosiu D, Petursdottir TE, Bjornsson J, Ingvarsson S, Ratcliffe PJ, Longmore GD, Sharp TV. The LIMD1 protein bridges an association between the prolyl hydroxylases and VHL to repress HIF-1 activity. Nat Cell Biol, 2012, 14: 201-208

33 Nilsson GE, Renshaw GM. Hypoxic survival strategies in two fishes: extreme anoxia tolerance in the North European crucian carp and natural hypoxic preconditioning in a coral-reef shark. J Exp Biol, 2004, 207: 3131-3139

34 Nilsson GE. Surviving anoxia with the brain turned on. News Physiol Sci, 2001, 16: 217-221

35 Lutz PL, Nilsson GE. Vertebrate brains at the pilot light. Resp Physiol Neurobiol, 2004, 141: 285-296

36 Stecyk JA, Stenslokken KO, Farrell AP, Nilsson GE. Maintained cardiac pumping in anoxic crucian carp. Science, 2004, 306: 77

37 Shoubridge EA, Hochachka PW. Ethanol: novel end product of vertebrate anaerobic metabolism. Science, 1980, 209: 308-309

38 Roesner A, Mitz SA, Hankeln T, Burmester T. Globins and hypoxia adaptation in the goldfish, Carassius auratus. FEBS J, 2008, 275: 3633-3643

39 Rytkonen KT, Akbarzadeh A, Miandare HK, Kamei H, Duan C, Leder EH, Williams TA, Nikinmaa M. Subfunctionalization of cyprinid hypoxia-inducible factors for roles in development and oxygen sensing. Evolution, 2013, 67: 873-882

40 Chi W, Gan X, Xiao W, Wang W, He S. Different evolutionary patterns of hypoxia-inducible factor alpha (HIF-alpha) isoforms in the basal branches of Actinopterygii and Sarcopterygii. FEBS Open Bio, 2013, 3: 479-483

41 Nilsson GE, Dymowska A, Stecyk JA. New insights into the plasticity of gill structure. Resp Physiol Neurobiol, 2012, 184: 214-222

42 Turko AJ, Cooper CA, Wright PA. Gill remodelling during terrestrial acclimation reduces aquatic respiratory function of the amphibious fish Kryptolebias marmoratus. J Exp Biol, 2012, 215: 3973-3980

43 Dhillon RS, Yao L, Matey V, Chen BJ, Zhang AJ, Cao ZD, Fu SJ, Brauner CJ, Wang YS, Richards JG. Interspecific differences in hypoxia-induced gill remodeling in carp. Physiol Biochem Zool, 2013, 86: 727-739

44 Tzaneva V, Vadeboncoeur C, Ting J, Perry SF. Effects of hypoxia-induced gill remodelling on the innervation and distribution of 
ionocytes in the gill of goldfish, Carassius auratus. J Comp Neurol, 2014, 522: 118-130

45 Mitrovic D, Dymowska A, Nilsson GE, Perry SF. Physiological consequences of gill remodeling in goldfish (Carassius auratus) during exposure to long-term hypoxia. Am J Physiol Regul Integr Comp Physiol, 2009, 297: R224-234

46 Zachar PC, Jonz MG. Oxygen sensitivity of gill neuroepithelial cells in the anoxia-tolerant goldfish. Adv Exp Med Biol, 2012, 758: $167-172$

47 Cameron JS, DeWitt JP, Ngo TT, Yajnik T, Chan S, Chung E, Kang E. Cardiac K(ATP) channel alterations associated with acclimation to hypoxia in goldfish (Carassius auratus L.). Comp Biochem Physiol A Mol Integr Physiol, 2013, 164: 554-564

48 Capossela KM, Brill RW, Fabrizio MC, Bushnell PG. Metabolic and cardiorespiratory responses of summer flounder Paralichthys dentatus to hypoxia at two temperatures. J Fish Biol, 2012, 81: 1043-1058

49 Feng X, Liu X, Zhang W, Xiao W. p53 directly suppresses BNIP3 expression to protect against hypoxia-induced cell death. EMBO J, 2011, 30: 3397-3415

50 Soitamo AJ, Rabergh CM, Gassmann M, Sistonen L, Nikinmaa M. Characterization of a hypoxia-inducible factor (HIF-1alpha) from rainbow trout. Accumulation of protein occurs at normal venous oxygen tension. J Biol Chem, 2001, 276: 19699-19705

51 Rahman MS, Thomas P. Molecular cloning, characterization and expression of two hypoxia-inducible factor alpha subunits, HIF-1alpha and HIF-2alpha, in a hypoxia-tolerant marine teleost, Atlantic croaker (Micropogonias undulatus). Gene, 2007, 396: 273-282

52 Rojas DA, Perez-Munizaga DA, Centanin L, Antonelli M, Wappner $\mathrm{P}$, Allende ML, Reyes AE. Cloning of HIF-1alpha and HIF-2alpha and mRNA expression pattern during development in zebrafish. Gene Exp Patterns, 2007, 7: 339-345

53 Shen RJ, Jiang XY, Pu JW, Zou SM. HIF-1alpha and -2alpha genes in a hypoxia-sensitive teleost species Megalobrama amblycephala: cDNA cloning, expression and different responses to hypoxia. Comp Biochem Physiol B Biochem Mol Biol, 2010, 157: 273-280

54 Cao YB, Chen XQ, Wang S, Wang YX, Du JZ. Evolution and regulation of the downstream gene of hypoxia-inducible factor-1alpha in naked carp (Gymnocypris przewalskii) from Lake Qinghai, China. J Mol Evol, 2008, 67: 570-580

55 Rytkonen KT, Vuori KA, Primmer CR, Nikinmaa M. Comparison of hypoxia-inducible factor-1 alpha in hypoxia-sensitive and hypoxia-tolerant fish species. Comp Biochem Physiol Part D Genomics Proteomics, 2007, 2: 177-186

56 Terova G, Rimoldi S, Cora S, Bernardini G, Gornati R, Saroglia M. Acute and chronic hypoxia affects HIF-1 alpha mRNA levels in sea bass (Dicentrarchus labrax). Aquaculture, 2008, 279: 150-159

57 Mohindra V, Tripathi RK, Singh RK, Lal KK. Molecular characterization and expression analysis of three hypoxia-inducible factor alpha subunits, HIF-1alpha, -2alpha and -3alpha in hypoxia-tolerant Indian catfish, Clarias batrachus [Linnaeus, 1758]. Mol Biol Rep, 2013, 40: 5805-5815

58 Geng X, Feng J, Liu S, Wang Y, Arias C, Liu Z. Transcriptional regulation of hypoxia inducible factors alpha (HIF-alpha) and their inhibiting factor (FIH-1) of channel catfish (Ictalurus punctatus) under hypoxia. Comp Biochem Physiol B Biochem Mol Biol, 2014, 169: $38-50$

59 Law SH, Wu RS, Ng PK, Yu RM, Kong RY. Cloning and expression analysis of two distinct HIF-alpha isoforms-gcHIF-1alpha and gcHIF-4alpha-from the hypoxia-tolerant grass carp, Ctenopharyngodon idellus. BMC Mol Biol, 2006, 7: 15

60 Rimoldi S, Terova G, Ceccuzzi P, Marelli S, Antonini M, Saroglia M. HIF-1alpha mRNA levels in Eurasian perch (Perca fluviatilis) exposed to acute and chronic hypoxia. Mol Biol Rep, 2012, 39: 4009-4015

61 Kaelin WG Jr., Ratcliffe PJ. Oxygen sensing by metazoans: the central role of the HIF hydroxylase pathway. Mol Cell, 2008, 30: 393-402

62 Kaelin WG, Sawyers CL, Mihich E. Nineteenth Annual Pezcoller Symposium: hypothesis-driven clinical investigation in cancer. Can- cer Res, 2007, 67: 11102-11105

63 Nikinmaa M, Rees BB. Oxygen-dependent gene expression in fishes. Am J Physiol Regul Integr Comp Physiol, 2005, 288: R1079-1090

64 van Rooijen E, Voest EE, Logister I, Korving J, Schwerte T, Schulte-Merker S, Giles RH, van Eeden FJ. Zebrafish mutants in the von Hippel-Lindau tumor suppressor display a hypoxic response and recapitulate key aspects of Chuvash polycythemia. Blood, 2009, 113: 6449-6460

65 Lindsley JE, Rutter J. Nutrient sensing and metabolic decisions. Comp Biochem Physiol B Biochem Mol Biol, 2004, 139: 543-559

66 Krumschnabel G, Biasi C, Wieser W. Action of adenosine on energetics, protein synthesis and $\mathrm{K}(+)$ homeostasis in teleost hepatocytes. J Exp Biol, 2000, 203: 2657-2665

67 Nilsson GE. The adenosine receptor blocker aminophylline increases anoxic ethanol excretion in crucian carp. Am J Physiol, 1991, 261: R1057-1060

68 Nilsson GE, Hylland P, Lofman CO. Anoxia and adenosine induce increased cerebral blood flow rate in crucian carp. Am J Physiol, 1994, 267: R590-595

69 Krumschnabel G, Schwarzbaum PJ, Lisch J, Biasi C, Wieser W. Oxygen-dependent energetics of anoxia-tolerant and anoxia-intolerant hepatocytes. J Exp Biol, 2000, 203: 951-959

70 Hermes-Lima M, Zenteno-Savin T. Animal response to drastic changes in oxygen availability and physiological oxidative stress. Comp Biochem Physiol Toxicol Pharmacol, 2002, 133: 537-556

71 Lushchak VI, Lushchak LP, Mota AA, Hermes-Lima M. Oxidative stress and antioxidant defenses in goldfish Carassius auratus during anoxia and reoxygenation. Am J Physiol Regul Integr Comp Physiol, 2001, 280: R100-107

72 Vig E, Gabrielak T, Leyko W, Nemcsok J, Matkovics B. Purification and characterization of $\mathrm{Cu}, \mathrm{Zn}$-superoxide dismutase from common carp liver. Comp Biochem Physiol B Biochem Mol Biol, 1989, 94: 395-397

73 Zhong XP, Wang D, Zhang YB, Gui JF. Identification and characterization of hypoxia-induced genes in Carassius auratus blastulae embryonic cells using suppression subtractive hybridization. Comp Biochem Physiol B Biochem Mol Biol, 2009, 152: 161-170

74 Liao X, Cheng L, Xu P, Lu G, Wachholtz M, Sun X, Chen S. Transcriptome analysis of crucian carp (Carassius auratus), an important aquaculture and hypoxia-tolerant species. PLoS One, 2013, 8: e62308

75 Everett MV, Antal CE, Crawford DL. The effect of short-term hypoxic exposure on metabolic gene expression. J Exp Zool A Ecol Genet Physiol, 2012, 317: 9-23

76 Chen K, Cole RB, Rees BB. Hypoxia-induced changes in the zebrafish (Danio rerio) skeletal muscle proteome. J Proteomics, 2013, 78: 477-485

77 Zhang Z, Wu RS, Mok HO, Wang Y, Poon WW, Cheng SH, Kong $\mathrm{RY}$. Isolation, characterization and expression analysis of a hypoxia-responsive glucose transporter gene from the grass carp, Ctenopharyngodon idellus. Eur J Biochem/FEBS, 2003, 270: 3010-3017

78 Hall JR, Richards RC, MacCormack TJ, Ewart KV, Driedzic WR. Cloning of GLUT3 cDNA from Atlantic cod (Gadus morhua) and expression of GLUT1 and GLUT3 in response to hypoxia. Biochim Biophys Acta, 2005, 1730: 245-252

79 Terova G, Forchino A, Rimoldi S, Brambilla F, Antonini M, Saroglia M. Bio-Mos: an effective inducer of dicentracin gene expression in European sea bass (Dicentrarchus labrax). Comp Biochem Physiol B Biochem Mol Biol, 2009, 153: 372-377

80 Chou CF, Tohari S, Brenner S, Venkatesh B. Erythropoietin gene from a teleost fish, Fugu rubripes. Blood, 2004, 104: 1498-1503

81 Chu CY, Cheng CH, Chen GD, Chen YC, Hung CC, Huang KY, Huang CJ. The zebrafish erythropoietin: functional identification and biochemical characterization. FEBS Lett, 2007, 581: 4265-4271

82 Paffett-Lugassy N, Hsia N, Fraenkel PG, Paw B, Leshinsky I, Barut B, Bahary N, Caro J, Handin R, Zon LI. Functional conservation of erythropoietin signaling in zebrafish. Blood, 2007, 110: 2718-2726

83 Pierron F, Baudrimont M, Gonzalez P, Bourdineaud JP, Elie P, Massabuau JC. Common pattern of gene expression in response to hypoxia or cadmium in the gills of the European glass eel (Anguilla 
anguilla). Environ Sci Technol, 2007, 41: 3005-3011

84 Vuori KA, Soitamo A, Vuorinen PJ, Nikinmaa M. Baltic salmon (Salmo salar) yolk-sac fry mortality is associated with disturbances in the function of hypoxia-inducible transcription factor (HIF-1alpha) and consecutive gene expression. Aquat Toxicol, 2004, 68: 301-313

85 Yu RM, Ng PK, Tan T, Chu DL, Wu RS, Kong RY. Enhancement of hypoxia-induced gene expression in fish liver by the aryl hydrocarbon receptor $(\mathrm{AhR})$ ligand, benzo[a]pyrene $(\mathrm{BaP})$. Aquat Toxicol, 2008, 90: 235-242

86 Wang D, Zhong XP, Qiao ZX, Gui JF. Inductive transcription and protective role of fish heme oxygenase-1 under hypoxic stress. J Exp
Biol, 2008, 211: 2700-2706

87 Stevenson TJ, Trinh T, Kogelschatz C, Fujimoto E, Lush ME, Piotrowski T, Brimley CJ, Bonkowsky JL. Hypoxia disruption of vertebrate CNS pathfinding through ephrinB2 is rescued by magnesium. PLoS Genet, 2012, 8: e1002638

88 Barriga EH, Maxwell PH, Reyes AE, Mayor R. The hypoxia factor Hif-1alpha controls neural crest chemotaxis and epithelial to mesenchymal transition. J Cell Biol, 2013, 201: 759-776

89 Zhang LL, Zhou Q. CRISPR/Cas technology: a revolutionary approach for genome engineering. Sci China Life Sci, 2014, 57: 639-640

Open Access This article is distributed under the terms of the Creative Commons Attribution License which permits any use, distribution, and reproduction in any medium, provided the original author(s) and source are credited. 